\title{
JUVENILE HORMONE INHIBITS DIFFERENTIATION OF OLFACTORY SENSE ORGANS DURING POSTEMBRYONIC DEVELOPMENT OF COCKROACHES
}

\author{
ROLLIE SCHAFER and THOMAS V. SANCHEZ \\ Department of Zoology, University of Michigan, Ann Arbor, Michigan 48104, U.S.A.
}

(Received 3 October 1973)

\begin{abstract}
The density of olfactory sense organs on the antenna of the cockroach, Leucophaea maderae, is relatively constant throughout larval development (average 400 sensilla $/ \mathrm{mm}^{2}$ ), but undergoes a substantial increase at the adult stage (to about 620 sensilla $/ \mathrm{mm}^{2}$ ). Experimental manipulations of juvenile hormone $(\mathrm{JH})$ activity result in either supernumerary larval instars (induced by unilateral antennectomy or addition of exogenous $\mathrm{JH}$ ), or premature adulthood (induced by allatectomy). The density of antennal sensilla remains at the larval level during the extra instars, but increases to the adult level or surpasses it at the terminal ecdysis following the induction of extra instars. Adultoids resulting from allatectomized sixth instars also have the high density of antennal olfactory sensilla characteristic of the normal adult. These data suggest that an interplay of surface area effects and an inhibitory action of JH controls the pattern of postembryonic development of antennal olfactory sensilla. Limited behavioural observations of the insects resulting from these experiments are consistent with the hypothesis that sex attractant-specific olfactory receptors appear only at the adult stage. However, electrophysiological data will be needed to confirm or negate this hypothesis.
\end{abstract}

\section{INTRODUCTION}

IT HAS been suggested that the major factor controlling the density of cuticular sensilla in insects is a circular zone of inhibition which each sensillum exerts to prevent the differentiation of new sensilla in adjacent cuticle (WIGGLESWORTH, 1940). A more recent suggestion, which is in line with the type of mechanism known to operate in other embryological field systems, is that groups of epidermal cells co-operatively determine the appearance of new cuticular sensilla (LAWRENCE, 1970). Regardless of the source and identity of the inhibitory or inductive influence, both of these hypothesized mechanisms depend directly on the amount of cuticular surface area present and the density of sensilla.

Juvenile hormone $(\mathrm{JH})$ also plays a rôle in regulating the differentiation of cuticular hairs in addition to its regulatory effect on other cuticular features (WIGGlesWorth, 1965). For example, WigGlesworth (1954) induced patches of larval cuticle bearing bristles by subcuticular implantation of corpora allata 
in adult Rhodnius, and LAWRENCE (1969) showed that the development of noninverted cuticular hairs in the milkweed bug, Oncopeltus, is inhibited by JH. We propose that an interplay of surface area effects and inhibitory action by $\mathrm{JH}$ determines the pattern of postembryonic development of antennal olfactory organs in the cockroach.

In the cockroach, Leucophaea maderae, the total number of antennal sense organs increases at an accelerating pace throughout larval development (SCHAFER, 1973). At the terminal ecdysis initiating the adult stage the total population of antennal sense organs increases by about 40 per cent in both males and females. Of this total population of $3 \cdot 4 \times 10^{4}$ sensilla, approximately 80 per cent are olfactory organs (sensilla trichodea and basiconica), 15 per cent are probably contact chemoreceptor organs (sensilla chaetica type $B$ ), and the remaining 5 per cent are mechanoreceptors or receptors of other sensory modalities. The large increase in antennal sensilla at the terminal ecdysis is almost entirely the result of a 67 per cent increase in the total number of olfactory sensilla on the antenna, from $1.6 \times$ $10^{4}$ in the last larval instar to $2.8 \times 10^{4}$ in the adult (SCHAFER, 1973).

Regeneration experiments on the antenna of Leucophaea seemed to suggest that the large increase in olfactory sensilla at the terminal ecdysis was due to the release of a partial inhibition by $\mathrm{JH}$ on the differentiation of new olfactory sensilla during larval development (ScHAFER, 1973). JH is secreted throughout larval development in Leucophaea, but its secretion ceases during the terminal instar. Disappearance of $\mathrm{JH}$ leads to the adult stage with its accompanying morphological, physiological, and behavioural characteristics (ScHARRER, 1946). The work reported in this paper concerns our attempts to clarify the possible rôle of JH in the differentiation of new olfactory sense organs in the antenna of Leucophaea. Accordingly, the density of antennal olfactory sensilla was examined during and after various experimental manipulations which resulted in changes in the level of $\mathrm{JH}$. Limited behavioural observations were also made in an attempt to determine the level of responsiveness of the experimental animals to possible sex attractants produced by the opposite sex.

\section{MATERIALS AND METHODS}

The data on normal development in the antenna of the cockroach, Leucophaea maderae $\mathrm{F}$., were taken from an earlier study (ScHafer, 1973). The data on the density of antennal sensilla in the present experiments were obtained using the same histological methods employed in earlier studies (SCHAFER, 1971, 1973). Absolute counts of sensilla on the nearly transparent antennae of newly ccdysed animals were used to compute the total number of the different kinds of antennal sensilla after different experimental manipulations of $\mathrm{JH}$ concentration. These data plus computations of antennal surface area were used to calculate the average density of the different kinds of sense organs on the surface of the antenna.

The effect of $\mathrm{JH}$ on the development of antennal sensilla was tested using three different methods which resulted in either prolonged larval development 
(through antennectomy or addition of $\mathrm{JH}$ ) or premature adulthood (through allatectomy of sixth instar larvae):

\section{Antennectomy experiments}

Physical damage in cockroaches often results in extended larval development (GUTHRIE and TINDALL, 1968). Amputation of a single antenna in the cockroach, L. maderae, usually results in the appearance of an extra (eighth) instar before the adult stage is reached (SCHAFER, 1973). In the antennectomy experiments reported here, a single antenna was removed during the seventh instar. The effects of antennectomy (and its resultant prolongation of larval development through continued secretion of $\mathrm{JH}$ ) were determined by calculating the density of sensilla on the intact antenna which had not been removed in the seventh instar.

\section{Allatectomy experiments}

Removal of the corpora allata which secrete $\mathrm{JH}$ was performed using the method described by ScharRer (1946). These operations were performed primarily on sixth instar larvae. A few seventh instar larvae were subjected to simultaneous antennectomy-allatectomy to determine the effects, if any, of the trauma of these operations on the adult pattern of sensilla.

\section{fuvenile hormone experiments}

The larval period of development was extended by placing a filter paper floor impregnated with $250 \mathrm{mg}$ of synthetic $\mathrm{JH}$ (Calbiochem, grade $\mathrm{B}$, activity about 1 per cent that of pure natural $\mathrm{JH}$ ) in the culture container. The filter paper (Whatman No. 1, dia. $14 \mathrm{~cm}$ ) covered the entire floor of the culture container and was reimpregnated every 3 weeks with $250 \mathrm{mg}$ of synthetic hormone. Adult insects were obtained subsequent to the prolongation of the larval period of development by removing them from the cultures containing synthetic $\mathrm{JH}$.

Behavioural observations were undertaken to determine which of the insects subjected to experimental alteration showed sexual behaviour characteristic of normal adults. Unfortunately, only a very small number of animals was available for behavioural tests, since most had necessarily been sacrificed for histological examination of the antennae. The sexual behaviour of Leucophaea has been described by ROTH and BARTH (1967). We have made extensive, unpublished observations on normal adults and larvae of Leucophaea and have generally confirmed their data.

Normal adults show stereotyped sexual pehaviour which includes the following kinds of activity: (1) Exploratory movements dccompanied by antennal waving in the presence of the opposite sex (females and occasionally males) (cf. RoTH and Barth, 1967). (2) Antennal stroking or fencing (both sexes). (3) Vertical vibration (males). (4) Wing pumping, wing raising, or abdominal arching (males). (5) Approach or flight of females in response to vertical vibration or wing raising in males. (6) Mounting (females) or backing (males). (7) Copulatory movements. 
Larvae show virtually none of the above activities, except for occasional exploratory movements in the presence of other cockroaches which need not be of the opposite sex. It should be noted that the sexual behaviour of Leucophaea is not nearly as clear-cut as in some other species of cockroaches such as Periplaneta americana, and that other stimuli can occasionally elicit activities which have been listed as sexual behaviour (e.g. exploratory movements and vertical vibration). The limited behavioural tests performed with the experimental animals produced in this study consisted primarily of simple observation of the insect's responses when presented with a normal adult of the opposite sex. The conditions of the behavioural tests were essentially those described by RoTH and BARTH (1967), except that virgin males and females were presented to the test animals as well as filter papers which had been exposed to virgin males and females.

\section{RESULTS}

Observations of normal development

Normal postembryonic development of the antennal sense organs of Leucophaea was described in an earlier study in terms of total numbers of sensilla per antenna (ScHAFER, 1973). For purposes of comparison with the experiments reported here, the pattern of normal development of the antennal sense organs is given as the density of sensilla on the antenna (Table 1, Figs. 1-3). The density of olfactory sensilla is fairly constant throughout larval development, but increases by 67 per cent at the adult ecdysis (Figs. 1-3). In contrast, the density of thickwalled chemoreceptors shows only a slight increase with the adult ecdysis and is somewhat less than the density in the six earlier instars (Table 1). Therefore, the pattern of development of the thin-walled olfactory sensilla is entirely different from that of the thick-walled contact chemoreceptors.

\section{Antennectomy experiments (Fig. 1)}

Complete removal of a single antenna in seventh instar larvae produced different effects in different animals, although all antennectomies were performed early in the instar, within 1 week of the seventh larval ecdysis. A few insects went directly to the adult stage at the next ecdysis, but most went into an extra (eighth) instar before becoming adults. The eighth instar larvae produced in this way were morphologically identical to normal seventh instar larvae, except that they were slightly larger and lacked most of the antenna which had been removed in the previous instar. Most eighth instar larvae became normal-appearing adults at the next ecdysis and had partially regenerated the amputated antenna. A few insects passed from the eighth larval instar to a ninth larval instar with morphological features resembling those of the eighth instar. Ninth instar larvae subsequently ecdysed to large, normal-appearing adults.

During the eighth instar, olfactory sensilla density did not rise above the normal larval level, but at the adult stage following the extra larval instar the density of 
Table 1-Normal development and mXPtrimental changes in THE Density OF thinWALIED OLFACTORY SENSILLA AND THICK-WALLED CHEMORECEPTORS ON THE ANTENNA OF L. maderae

\begin{tabular}{|c|c|c|c|}
\hline \multirow[b]{2}{*}{ Stage } & \multirow{2}{*}{$\begin{array}{l}\text { No. of } \\
\text { antennae } \\
\text { counted }\end{array}$} & \multicolumn{2}{|c|}{$\begin{array}{c}\text { Average density } \\
\left.\text { (no. of sensilla/mm } / \mathrm{mm}^{2}\right)\end{array}$} \\
\hline & & $\begin{array}{l}\text { Thin-walled } \\
\text { olfactory sensilla }\end{array}$ & $\begin{array}{l}\text { Thick-walled } \\
\text { chemoreceptors }\end{array}$ \\
\hline First instar (normal) & 6 & 474 & 232 \\
\hline Second instar (normal) & 6 & 405 & 222 \\
\hline Third instar (normal) & 6 & 357 & 175 \\
\hline Fourth instar (normal) & 6 & 409 & 172 \\
\hline Fifth instar (normal) & 6 & 368 & 147 \\
\hline Sixth instar (normal) & 5 & 447 & 131 \\
\hline Seventh instar (normal) & 5 & 371 & 96 \\
\hline Adult (normal) & 6 & 620 & 117 \\
\hline $\begin{array}{l}\text { Adult (from seventh instar, anten- } \\
\text { nectomy) }\end{array}$ & 3 & 801 & 127 \\
\hline Eighth instar (antennectomy) & 3 & 349 & 111 \\
\hline $\begin{array}{l}\text { Adult (from eighth instar, anten- } \\
\text { nectomy) }\end{array}$ & 3 & 895 & 134 \\
\hline Ninth instar (antennectomy) & 2 & 500 & 104 \\
\hline $\begin{array}{l}\text { Adult (from ninth instar, antennec- } \\
\text { tomy) }\end{array}$ & 2 & 1150 & 169 \\
\hline Adultoid (allatectomy in sixth instar) & 4 & 837 & 246 \\
\hline $\begin{array}{l}\text { Adult (sham allatectomy in sixth } \\
\text { instar) }\end{array}$ & 3 & 692 & 146 \\
\hline $\begin{array}{l}\text { Adult (allatectomy-antennectomy in } \\
\text { seventh instar) }\end{array}$ & 3 & 812 & 205 \\
\hline $\begin{array}{l}\text { Eighth instar (juvenile hormone-in- } \\
\text { duced) }\end{array}$ & 4 & 470 & 123 \\
\hline $\begin{array}{l}\text { Adult (from JH-induced eighth } \\
\text { instar) }\end{array}$ & 4 & 1164 & 203 \\
\hline Larvoid (JH-induced) & 2 & 432 & 102 \\
\hline $\begin{array}{l}\text { Semi-adult (from eighth instar under } \\
\text { influence of } \mathrm{JH} \text { ) }\end{array}$ & 4 & 773 & 142 \\
\hline
\end{tabular}

olfactory sensilla rose by 157 per cent (Fig. 1). In the few insects which passed through two extra larval stages, the density of olfactory sensilla remained near the larval level during the supernumerary instars. The density of olfactory sensilla on the antennae of adults resulting from the ecdysing of ninth instar larvae increased by 130 per cent over the density on ninth instar larvae (Fig. 1). In the few instances where an antennectomized seventh instar larva went directly to the adult stage, olfactory sensilla density increased by 116 per cent. Likewise, performing both antennectomy and allatectomy on seventh instar larvae resulted in an increase of 119 per cent in the density of olfactory sensilla at the ensuing ecdysis (Fig. 1). 


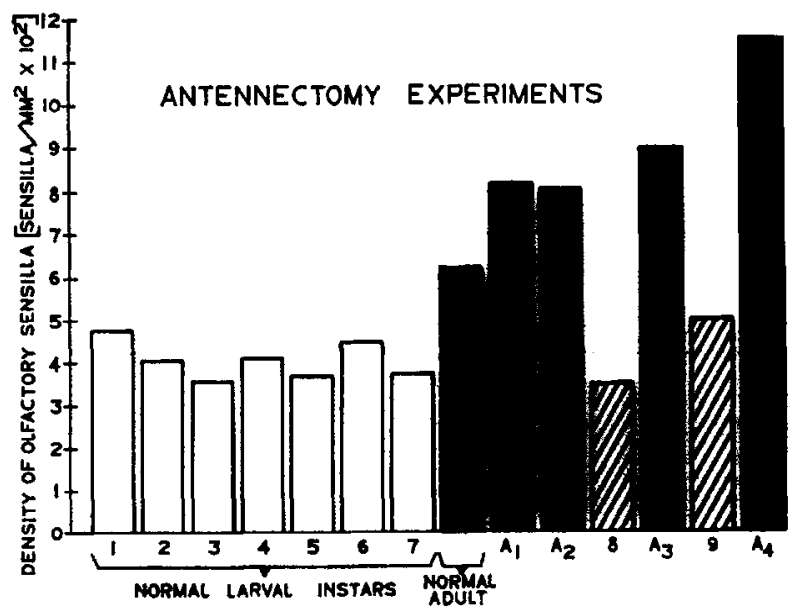

FIG. 1. Antennectomy experiments. The density of olfactory sensilla is shown for the normal larval instars (white bars), supernumerary instars (cross-hatched bars), and adults (black bars). $A_{1}$, Adult derived from seventh instar antennectomy-allatectomy; $A_{2}$, adult derived directly from seventh instar antennectomy;

$A_{3}$, adult derived from eighth instar; $A_{4}$, adult derived from ninth instar.

\section{Allatectomy experiments (Fig. 2)}

Removal of the corpora allata in the sixth instar resulted in the appearance of an adultoid at the following ecdysis. These insects had all the morphological characteristics of the normal adult, albeit in somewhat reduced form (cf. SCHARRRR, 1946). The density of antennal olfactory sensilla in adultoids showed an increase of 87 per cent over that of the normal sixth instar larva and was greater than the density in normal adults (Fig. 2). Allatectomy-antennectomy in the seventh instar led to an increase of 119 per cent, as noted previously.

\section{fuvenile hormone experiments (Fig. 3)}

Exposure of normal seventh instar larvae to synthetic JH in their culture container resulted in prolongation of larval development and the appearance of extra (eighth) instars. Most of the eighth instar larvae which emerged in the presence of synthetic $\mathrm{JH}$ were morphologically identical to normal seventh instar larvae, although slightly larger. The use of synthetic $\mathrm{JH}$ also resulted in the occasional appearance of two other forms with some adult characteristics. A larval form which we call a larvoid had incipient wings, but no other adult characteristics. Another form which we call a semi-adult also appeared with a mixture of adult and larval characteristics. The semi-adults were derived from eighth instar larvae left in the presence of synthetic $\mathrm{JH}$ and had large wings and antennal segmentation characteristic of the normal adult, but also had many larval characteristics in other body features. For example, no tergal gland was present in male 


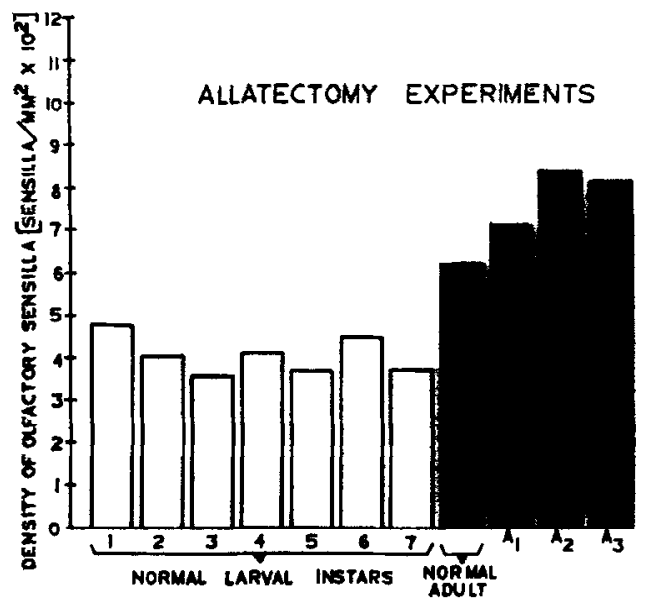

FIG. 2. Allatectomy experiments. The density of olfactory sensilla is shown for the normal larval instars (white bars) and adultoids or adults (black bars) derived from allatectomy or sham operation. $A_{1}$, Adult from sham allatectomy performed in sixth instar; $A_{2}$, adultoid derived from allatectomy performed in sixth instar; $A_{3}$, adult derived from antennectomy-allatectomy performed in seventh instar.

semi-adults and the genitalia were poorly developed. The pronotum of semiadults also had a larval shape and the surface of the cuticle lacked the waxy appearance of adult cuticle.

The density of olfactory sensilla in eighth instar larvae produced by exposure to synthetic JH remained at the larval level (Fig. 3). At the adult stage following the eighth instar (and the removal of exogenous $\mathrm{JH}$ ), the density of antennal olfactory sensilla increased by 50 per cent over the eighth instar (Fig. 3). The density of olfactory sensilla on larvoid antennae remained at the larval level (Fig. 3). On the other hand, olfactory sensilla density on the antennae of semiadults was similar to that of the adult: 64 per cent greater than the density in eighth instar larvae and 108 per cent greater than in normal seventh instar larvae (Fig. 3). The adult pattern of sensilla density was accompanied by antennal segmentation similar to that of the adult. In semi-adults the third antennal segment (or meriston) was much shorter than that of seventh and eighth instar larvae. This segment is one of the sources of new segments during antennal growth in cockroaches and is always much shorter in adults than in larvae (SCHAFER, 1973).

\section{Behavioural observations}

Behavioural observations of several supernumerary larvae of both sexes produced by either antennectomy or the application of exogenous $\mathrm{JH}$ showed entirely larval behaviour (i.e. none of the adult responses listed previously). In contrast, adults produced in the antennectomy and $\mathrm{JH}$ experiments and adultoids produced by allatectomy in the sixth instar all showed responses at or near the 


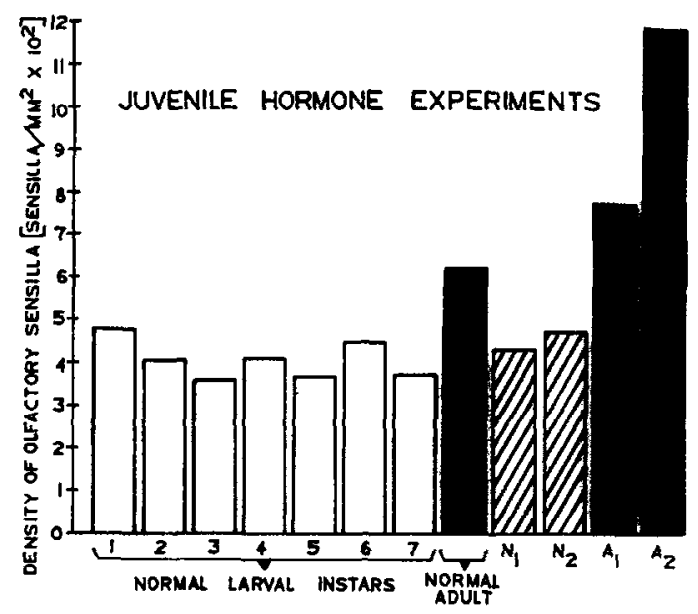

FIG. 3. Juvenile hormone experiments. The density of olfactory sensilla is shown for the normal larval instars (white bars), supernumerary larvae or larvoids (cross-hatched bars), and normal adults, semi-adults, and adults derived from eighth instar larvae after the removal of exogenous $\mathrm{JH}$ (black bars). $\mathrm{N}_{1}$, Larvoid derived from normal seventh instar by exposure to exogenous $\mathrm{JH} ; \mathrm{N}_{2}$, eighth instar larva derived from normal seventh instar by exposure to exogenous $\mathrm{JH}$; $A_{1}$, semi-adult derived from eighth instar under influence of exogenous $\mathrm{JH}$;

$A_{2}$, adult derived from eighth instar larva after removal of exogenous $\mathrm{JH}$.

adult level. The only exceptions to this pattern were the semi-adults produced from eighth instar larvae under the influence of $\mathrm{JH}$. These insects, despite having adult antennae and wings, displayed none of the responses characteristic of normal adult sexual behaviour.

\section{DISCUSSION}

During the normal development of the antennal sensory system of Leucophaea, the total number of olfactory sensilla increases by 67 per cent at the terminal ecdysis leading to the adult stage. This great increase in the olfactory component of the antenna can be partially explained by a large increase in the antennal surface area which occurs in the last larval ecdysis preceding the terminal ecdysis (ScHAFER, 1973). However, the packing or density of sensilla on the antennal surface also increases by approximately 70 per cent at the terminal ecdysis. This finding indicates that the régime which manages the distribution of olfactory organs on the antenna undergoes a basic change in the terminal instar leading to the adult ecdysis. This inductive influence is limited to olfactory sensilla, since no increase occurs in the thick-walled chemoreceptors which are probably gustatory and tactile organs (Table 1; ScHaFER, 1971).

The major hormonal event accompanying the terminal ecdysis in hemimetabolous insects such as Leucophaea is cessation of JH secretion (ScHARRER and ScharRer, 1963). We propose that the proliferation of olfactory sensilla at the terminal ecdysis is a result of the release of inhibition by $\mathrm{JH}$. In each instance 
where $\mathrm{JH}$ was experimentally maintained, either by antennectomy or supplying exogenous hormone, the population density of olfactory sensilla remained at the larval level (Figs. 1,3). When sources of $\mathrm{JH}$ were eliminated, the density of olfactory sensilla increased substantially, usually doubling (Figs. 2, 3). This increase occurred both when the removal of $\mathrm{JH}$ sources was premature (as in allatectomy), or subsequent to a period of extended larval development (as in the experiments where exogenous hormone was introduced or antennectomy was performed).

The morphological experiments thus establish a causal relationship between the pattern of development of the antennal olfactory system and the widespread morphogenetic effects of $\mathrm{JH}$. However, the morphological studies leave at least two important questions unanswered. First, the biochemical mechanism and site of action of the inhibitory influence of $\mathrm{JH}$ is unknown; second, it is not apparent from morphological examination whether olfactory receptors which appear at the adult stage are qualitatively different from those present during larval development. It might be reasonable to expect that sex attractant-specific receptors occur only in the adult stage, and that their development is suppressed in larvae by a selective influence of $\mathrm{JH}$. However, no morphological differences have been noted between Jarval and adult olfactory sensilla in Leucophaea (SCHAFER, 1973), nor has sufficient electrophysiological work been done on the antennal receptors of this species.

ROTH and BARTH (1967) found that the initiation of female sexual behaviour in Leucophaea seems to depend on the perception of an airborne sex pheromone liberated by the male. They found no substantive evidence for a female-produced pheromone. The morphological similarity between male and female antennae in Leucophaea (ScHAFER, 1973) would seem to be more consistent with the hypothesis that both sexes respond to a sex attractant produced by the opposite sex. In the cockroach, $P$. americana, only the female produces a sex attractant (RoTH and WILLIS, 1952). Male and female larvae of Periplaneta have identical numbers of antennal olfactory sensilla, but at the terminal ecdysis the population of olfactory sensilla on male antennae increases by 138 per cent while the female increases by only 36 per cent (SCHAFER and SANCHEZ, 1973). In this species, then, production of a sex attractant by only one of the sexes is accompanied by a great degree of sexual dimorphism in the number of antennal olfactory receptors on adult antennae. The situation is clearly different in Leucophaea, but the reasons behind this difference are not as yet understood.

The behavioural observations were greatly limited by the small number of insects available for testing, and thus any conclusions drawn from these data should be viewed with caution. Keeping this caveat in mind, a pattern may be noted in that nearly all of the insects with the high density of olfactory sensilla which is characteristic of normal adults showed a positive response to normal adults of the opposite sex or to filter papers exposed to virgin adults of the opposite sex. Insects with the low density of olfactory sensilla characteristic of the larval stage of development did not respond. Semi-adults did not respond, although 
they possess the adult complement of olfactory sensilla. A likely explanation for this exception is that although pheromone-specific peripheral receptors might be present in semi-adults (since the morphology of their antennae is entirely like that of the adult), some necessary central process or processes have not been activated.

The morphological data and the limited behavioural observations generally agree with the results which would be expected if pheromone-specific olfactory specialist receptors differentiate only in the adult antenna. However, such observations do not necessarily constitute support for this hypothesis. The observed behaviour in particular is a reflection of both central and peripheral nervous activities. The presence of olfactory specialist receptors on the antennae is probably a necessary, but not sufficient, condition for the initiation of adult sexual behaviour ( $c f$. SCHNEIDER, 1969). Electrophysiological recording will be needed to settle the question. If it turns out that pheromone specialists are found only in adult antennae, it follows that $\mathrm{JH}$ is the agent which controls the appearance of the specialist receptors necessary to adult sexual behaviour.

Acknowledgements-We thank Dr. William J. Bell and Dr. Eleanor H. Slifer for a critical review of the manuscript. This work was supported in part by N.S.F. Grant No. GB-32008 to R. SCHAFER.

\section{REFERENCES}

Guthrie D. M. and Tindall A. R. (1968) The Biology of the Cockroach, p. 102. St. Martin's, New York.

LAWRENCE P. A. (1969) Cellular differentiation and pattern formation during metamorphosis of the milkweed bug, Oncopeltus. Devel. Biol. 19, 12-40.

LAWRENCE P. A. (1970) Polarity and patterns in the postembryonic development of insects. Adv. Insect Physiol. 7, 197-266.

Roth L. M. and Barth R. H. (1967) The sense organs employed by cockroaches in mating behavior. Behaviour 28, 58-95.

Rorh L. M. and Willis E. R. (1952) A study of cockroach behavior. Am. Midl. Nat. 47, 66-129.

SCHAFER R. (1971) Antennal sense organs of the cockroach, Leucophaea maderae. F. Morph. 134, 91-103.

Schafer R. (1973) Postembryonic development in the antenna of the cockroach, Leucophaea maderae: growth, regeneration and the development of the adult pattern of sense organs. F. exp. Zool. 183, 353-363.

SchafER R. and SANChEZ T. V. (1973) Antennal sensory system of the cockroach, Periplaneta americana: postembryonic development and morphology of the sense organs. 7. comp. Neur. 149, 335-354.

Scharrer B. (1946) The role of the corpora allata in the development of Leucophaea maderae (Orthoptera). Endocrinol. 38, 35-45.

SCharrer E. and Scharrer B. (1963) Neuroendocrinology. Columbia University Press, New York.

SCHNEIDER D. (1969) Insect olfaction: deciphering system for chemical messages. Science $163,1031-1037$.

WIGGLESWORTH V. B. (1940) Local and general factors in the development of 'pattern' in Rhodnius prolixus (Hemiptera). F. exp. Biol. 17, 180-200.

WigglesworTh V. B. (1954) Secretion of juvenile hormone by the corpus allatum of Calliphora. Nature, Lond., 174, 556.

Wigglesworth V. B. (1965) The Principles of Insect Physiology, 6th ed., pp. 68-70. Methuen, London. 